\title{
The Impact of Program Improvement Using Forest Healing Resources on the Therapeutic Effect: Focused on Improving Index of Greenness for Adolescents
}

\author{
Joo-Ho Hwang, Hyo-Jung Lee, Jin-Hwa Park, Dong-Min Kim, and Kyoung-Min Lee* \\ National Center for Forest Therapy, Yeong-ju 36043. Korea
}

ABSTRACT

This study is to examine the effect of improving the forest therapy program for adolescents using forest healing resources (focused on improving index of greenness for adolescents). The participants were 30 students from in the control group that participated in the 2018 program, and 51 students in experimental group that participated in the improved program in 2019. The questionnaire, developed by Korea Forest Welfare Institute, was comprised of items on general matters, index of greenness, restorative environment, positive emotion, negative emotion, facial expression and psychological assessment. The control group had 30 and the experimental group had 49 valid copies of the questionnaires. As a result of the paired sample t-test for each group, the control group showed a significant increase in all categories except restorative environment. In the experimental group, all categories significantly improved to a higher level ( $p<.01)$.

An independent sample t-test (one-tailed test) was performed to test the effect of the forest therapy program with improved index of greenness. As a result, the index of greenness increased by 0.73 points $(\mathrm{t}=2.555, p<.01)$ and restorative environment by 1.01 points ( $\mathrm{t}=2.567, p<.01)$, showing statistical significance. Negative emotion increased by 0.04 points $(\mathrm{t}=0.183, p\rangle .05)$, which was not significant. On the other hand, positive emotion decreased by 0.42 points $(\mathrm{t}=-1.918, p<.05)$, facial expression by 0.57 points $(\mathrm{t}=-1.775, p\langle .05)$, and psychological assessment by 0.29 points $(\mathrm{t}=-0.981, p\rangle .05)$, showing significance in positive emotion and facial expression. However, all the decreased items showed significant improvements between the pretest and posttest scores of the experimental group.

Keywords: forest healing, forest therapy program, healing in forest, improvement effect

\section{Introduction}

Adolescence is the time when self-esteem and ego identity are formed and thus requires holistic growth and self-initiated activities. It is also the time when there are frequent emotional changes and sensitivity, thereby needing empathy and understanding. However, most adolescents in Korea lack time for identity improvement and emotional stability due to competitive education focused only on college entrance examination.

According to a social survey released by Statistics Korea in 2016, 49.9\% of adolescents in Korea claimed they are stressed. In particular, $54.4 \%$ of high school students seemed to be feeling stressed (Statistics Korea, 2016). When the survey was taken again in 2018, it was found that $51.9 \%$ of adolescents were feeling stressed, $56.4 \%$ of which were high school students, indicating that the percentage of students feeling stressed increased by $2.0 \%$ each (Statistics Korea, 2018). The increase in the response rate for perceived stress shows that adolescents are failing to properly relieve their stress (Kim et al., 2005). Adolescents are stressed by personal, familial and interpersonal rela-

Received: November 29, 2019, Revised: December 3, 2019, Accepted: December 4, 2019

First author: Joo-Ho Hwang, hwangjooho@fowi.or.kr, (10) https://orcid.org/0000-0002-8643-3434

*Corresponding author: Kyoung-Min Lee, snow1133@fowi.or.kr, (1D) https://orcid.org/0000-0002-1276-8848 
tions, and this accumulated stress may lead to psychosomatic illnesses such as headache and abdominal pain (Kim, 2006). In particular, when exposed to a high level of stress, many of them just assume that there is no problem in everyday life and go on with their life without taking proper measures, which causes physical and mental problems (Delongis et al., 1982; Kanner et al., 1981; Kwon, 2018).

Illnesses caused by stress inevitably require medical treatment, which is why it is very important to resolve and prevent them in advance. Recently, more and more people are alleviating stress or enjoying repose with forest therapy. In the past, forests had been perceived merely as lumber resources or places to relax, but recently, due to the medical limitations and value shift about natural medicine, forests are now regarded as health and medical healing spaces to promote health (Korea Forest Service, 2011). The change in perception about forests increased the demand for forest therapy, while also constantly increasing forest welfare facilities accordingly.

Studies on the effects of forests on human health discovered that forest landscape has positive effects on patient recovery (Park, 2010; Ulrich, 1984; Wells and Evans, 2003). Taking a walk in the forest or viewing scenery is effective in reducing the level of stress hormones and increasing comfort (Park, 2010). The effect of viewing scenery has impact on mental stability with not only direct experience but also indirect experience such as looking at forest images or listening to the sounds (Jeon and Shin, 2017). Moreover, as a result of showing images with increased index of greenness to adolescents, it was effective in emotional recovery (Song, 2010). As such, green is the main visual resource among the healing resources of forests, and visual stimulation through the index of greenness has positive effects on mind and body. Moreover, there are cases in which forest therapy programs brought improvement to depression, anxiety, stress, self-esteem, anger and aggression of adolescents (Kim et al., 2013).

Therefore, this study improves the index of greenness of indoor and outdoor forest therapy programs using healing resources and determines the impact of such improvement on increasing the therapeutic effect of adolescents. The index of greenness was increased so that participants can focus on viewing the forest for the outdoor program and indirectly appreciate the forest for the indoor program.

\section{Research Methods}

\section{Subjects}

The subjects of this study are adolescents aged 9 to 18 in Korea Green Ranger that participated in the two-day camp of the National Center for Forest Therapy in 2018 and 2019. We assigned 30 students that participated in the program in 2018 (Program A) to the control group and 51 students that participated in the index of greenness improvement program in 2019 (Program B) to the experimental group. Since the subjects of the two groups that were randomly sampled are not equivalent, the test for homogeneity of variance was conducted to verify the homogeneity of the two groups.

\section{Content of the forest therapy program}

The two-day camp schedule is the same for the two groups, and the forest therapy program excluding Korea Green Ranger's own program is comprised of the Forest Path Program (Program A-1, B-1) and Balance Therapy Program (Program A-2, B-2).

Since Program A and Program B have the same time structure, the exposure time to the forest is the same, but Program B in which the experimental group participated had its main content improved so that the index of greenness could be increased with focus on viewing scenery (Table 1).

\section{Forest Path Program using green landscape (Program B-1)}

Programs A-1 and B-1 were carried out on the Masil Healing Forest Path deck road of the National Center for Forest Therapy. Program A-1 is focused on taking walks including simple activities such as warmup exercises, walking along the forest path, and framing shots with fingers. On the other hand, the 2019 program was redesigned to focus more on viewing green landscape by adding visual stimulation and meditation activities such as 10 minutes 
Table 1. The comparison of Program A and B

\begin{tabular}{|c|c|c|}
\hline Curriculum & Program A for Control group & Program B for Experimental group \\
\hline \multirow{3}{*}{$\begin{array}{c}\text { Forest Path } \\
\text { Program } \\
(2 \mathrm{hrs})\end{array}$} & Program A-1 & Program B-1 \\
\hline & Warming up, forest walk, finger framing & Warming up, forest walk, finger framing \\
\hline & & $\begin{array}{l}\text { Green visual stimulation (50 min) } \\
\text { - Eye warm up (10 } \mathrm{min}) \\
\text { - Staring at forest (20 min) } \\
\text { - Staring at tree crown (20 min) }\end{array}$ \\
\hline \multirow{3}{*}{$\begin{array}{c}\text { Balance Therapy } \\
\text { Program } \\
(2 \mathrm{hrs})\end{array}$} & Program A-2 & Program B-2 \\
\hline & $\begin{array}{l}\text { Stretching, instrument massage, } \\
\text { log meditation }\end{array}$ & $\begin{array}{l}\text { Stretching, instrument massage, } \\
\text { log meditation }\end{array}$ \\
\hline & & Forest images, natural sounds ( $1 \mathrm{hr}$ ) \\
\hline
\end{tabular}

of eye-relaxing warmup exercises to promote visual stimulation, 20 minutes of viewing the forest by diversifying the vision, and 20 minutes of staring at the tree crown.

Program A-1 is based on activities that focus on walking in the forest. On the other hand, Program B-1 induced intensive viewing of scenery by enabling participants to see the entire forest at a long distance or see the tree crown at a short range (Fig. 1). This is to maximize the effect of visual stimulation with focused view of greenness. Scenarios are distributed to the instructors for smooth implementation of the program after redesigning it.

\section{Indoor program implementing realism of a real forest (Program B-2)}

Programs A-2 and B-2 were carried out indoors instead of in the forest, comprised of stretching, massaging with tools, and log meditation. While Program B-1 was to increase the effect of viewing green landscape, Program B-2 is more of an aid to maintain the visual stimulation effect through Program B-1. Moreover, the outdoor program may not be available due to weather conditions, which is why the indoor program is also applied to replace it. During the log meditation that is performed lying down, visual and auditory stimulations were given by the image of forest landscape on the ceiling and sounds of nature, thereby providing realism of a real forest so that the participants could indirectly feel the actual forest even during the indoor program (Fig. 2).

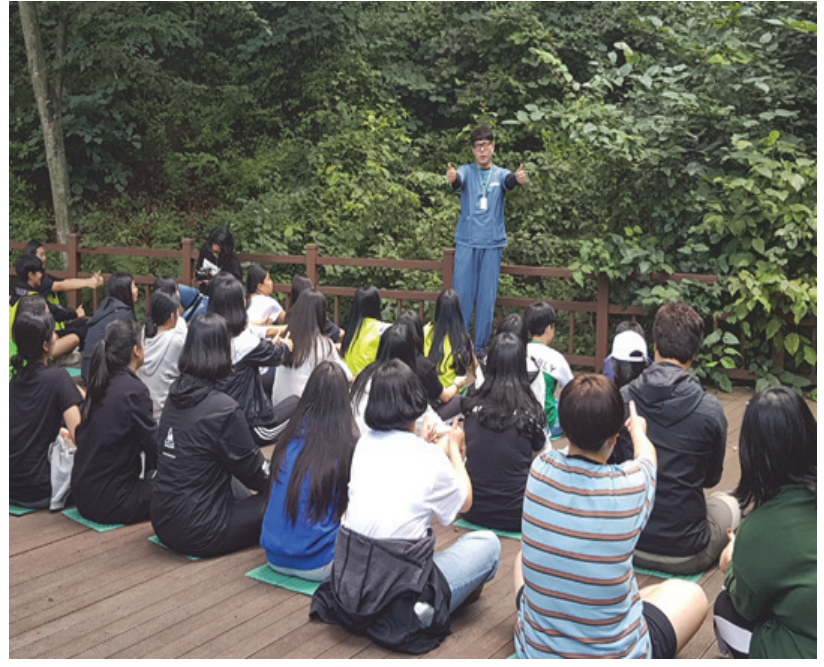

Fig. 1. Forest Path Program (Program B-1).

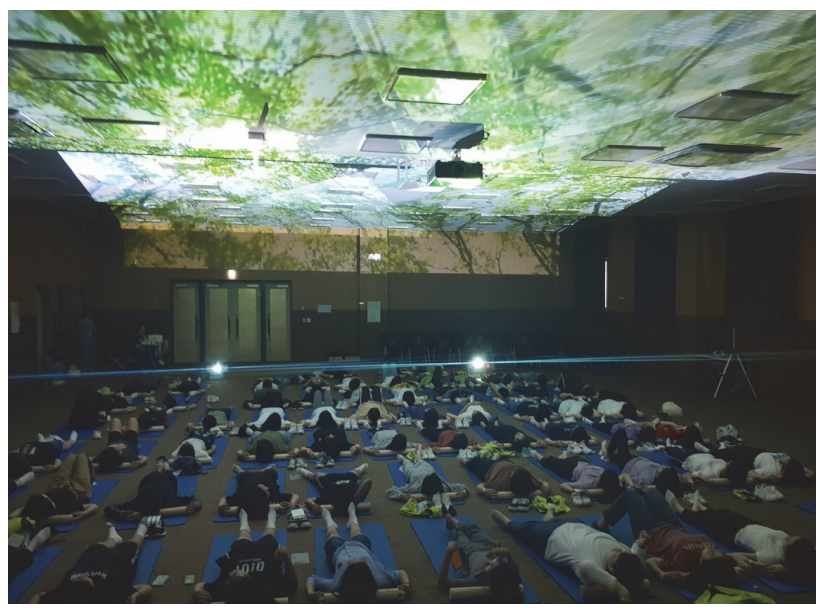

Fig. 2. Balance Therapy Program (Program B-2). 


\section{Measurement tools}

As a measurement tool, we used the pretest-posttest questionnaire of the 'Survey on the Effectiveness of Forest Welfare Programs' developed by Korea Forest Welfare Institute. The items consist of general matters (participating organization, gender, etc.) and six categories to verify the effect of forest therapy (index of greenness, restorative environment, positive emotion, negative emotion, facial expression, psychological assessment).

Index of greenness is measured by presenting color photos divided into six levels depending on green area and having the subjects choose the index of greenness perceived by them before and after the program. Restorative environment is measured by rating five items, such as escape from daily routines at the program site and space preference, on a 10-point scale. Positive emotion and negative emotion are measured by rating 10 items about emotions or moods on a 5-point Likert scale. Facial expression is measured by presenting images of facial expressions smiling broadly to frowning and having the subjects rate the expression similar to their current expression on a 7-point Likert scale. Psychological assessment is performed by rating six items about stress, happiness, etc. on a 7-point Likert scale.

\section{Data analysis}

IBM SPSS 24.0 program is used for all analyses of this study. For statistical analysis of means, we analyzed 30 copies from the control group with one missing value, and 49 copies from the experimental group excluding the ones with missing values. The paired sample t-test is performed in each category to verify the effect of forest therapy for each year.

To determine the impact of program improvement on increasing the therapeutic effect, we first conducted the test for homogeneity of variance on the experimental group and control group with different subjects to verify the homogeneity of the two groups, and conducted the independent samples t-test (one-tailed test) on the score differences for each category before and after the program.

\section{Results and Discussion}

\section{Results of subject analysis}

Total 30 copies of the questionnaire from 2018 and 51 from 2019 were collected, and 30 copies and 49 copies were analyzed excluding missing values. In 2018 there were 10 male and 20 female students, and in 2019 there were 20 male and 29 female students, indicating that the ratio of female students was higher in both groups (Table 2).

The test for homogeneity of variance was conducted to verify the homogeneity of the experimental group and control group. As a result, variance was presumed to be equal between both groups in the index of greenness, restorative environment, negative emotion, and psychological assessment, thereby proving homogeneity (Table 3 ). However,

Table 2. Gender characteristics of participants

\begin{tabular}{cccccc}
\hline \multirow{2}{*}{ Variable } & \multicolumn{2}{c}{ Control group } & & \multicolumn{2}{c}{ Experimental group } \\
\cline { 2 - 3 } \cline { 5 - 6 } & Frequency & $\begin{array}{c}\text { Percent } \\
(\%)\end{array}$ & & Frequency & $\begin{array}{c}\text { Percent } \\
(\%)\end{array}$ \\
\hline Male & 10 & 33.3 & & 20 & 40.8 \\
Female & 20 & 66.7 & & 29 & 59.2 \\
\hline
\end{tabular}

Table 3. The homogeneity of variance test between control and experimental group

\begin{tabular}{|c|c|c|c|c|c|c|}
\hline \multirow{2}{*}{ Item } & \multicolumn{2}{|c|}{ Control } & \multicolumn{2}{|c|}{ Experimental } & \multicolumn{2}{|c|}{ homogeneity of variance test } \\
\hline & $\mathrm{M}$ & $\mathrm{SD}$ & M & $\mathrm{SD}$ & $\mathrm{F}$ & $p$ \\
\hline Index of greenness & 2.21 & 1.24 & 2.94 & 1.22 & 0.784 & .379 \\
\hline Restorative environment & 0.42 & 2.00 & 1.44 & 1.49 & 0.414 & .522 \\
\hline Positive emotion & 0.87 & 1.07 & 0.45 & 0.72 & 4.299 & .041 \\
\hline Negative emotion & 0.81 & 1.10 & 0.85 & 0.72 & 3.137 & .081 \\
\hline Facial expression & 1.43 & 1.61 & 0.86 & 0.96 & 10.201 & .002 \\
\hline Psychological assessment & 1.54 & 1.56 & 1.25 & 1.11 & 0.775 & .381 \\
\hline
\end{tabular}


positive emotion and facial expression in which equal variance was not presumed had their significance determined by the values of analysis when equal variance is not presumed in the independent samples t-test.

\section{Results of analyzing the effect of forest therapy by year}

As a result of conducting a paired sample t-test on the survey before and after the program to test the effect of forest therapy, it was found that the control group showed increased scores in all six categories after the program, and five of them except restorative environment had statistically significant effect. The perfect score for each item is different and thus the scores were converted to the basis of 100 points. The results showed that index of greenness showed the greatest change and restorative environment showed the smallest change (Table 4).
A study comparing models about the effect of index of greenness on improving emotions proved that participants find places with high index of greenness charming, and these places have positive effects on emotions (Lee, 2007). This is consistent with the result of this study in which index of greenness and psychological assessment showed great changes.

The experimental group also showed increased scores in all six categories after the program, and there were statistically significant effects at $1 \%$ significance level. The result of comparing the scores on the basis of 100 points showed that index of greenness showed the biggest change (Table 5).

As a result of analyzing the effect of forest therapy by year, both groups showed increased scores after the program. Scores in index of greenness, psychological assessment, positive emotion, and negative emotion especially increased with statistical significance, which is consistent with pre-

Table 4. The effects of Program A for Control group ( $N=30)$

\begin{tabular}{|c|c|c|c|c|c|c|c|c|c|}
\hline \multirow{2}{*}{ Item } & \multicolumn{2}{|c|}{ Pre } & \multicolumn{2}{|c|}{ Post } & \multicolumn{2}{|c|}{ Post-Pre } & \multirow{2}{*}{$\mathrm{t}$} & \multirow{2}{*}{$p$} & \multirow{2}{*}{$\mathrm{df}$} \\
\hline & M & SD & M & SD & M & SD & & & \\
\hline Index of greenness ${ }^{z}$ & $2.62(43.68)$ & 0.82 & $4.83(80.46)$ & 1.44 & $2.21(36.78)$ & 1.24 & 9.617 & $.000^{* *}$ & 28 \\
\hline Restorative environment & 7.61(76.07) & 1.77 & $8.03(80.33)$ & 1.97 & $0.42(4.26)$ & 2.00 & 1.170 & .252 & \\
\hline Positive emotion & $3.07(61.46)$ & 0.84 & $3.94(78.89)$ & 0.89 & $0.87(17.43)$ & 1.07 & 4.450 & $.000^{* *}$ & \\
\hline Negative emotion & $3.36(67.21)$ & 0.83 & $4.17(83.45)$ & 1.06 & $0.81(16.24)$ & 1.10 & 4.030 & $.000^{* *}$ & 29 \\
\hline Facial expression & $2.30(32.86)$ & 1.29 & $3.73(53.33)$ & 1.70 & $1.43(20.47)$ & 1.61 & 4.870 & $.000^{* *}$ & \\
\hline Psychological assessment & $3.85(55.00)$ & 1.53 & $5.39(77.06)$ & 1.35 & $1.54(22.06)$ & 1.56 & 5.406 & $.000^{* *}$ & \\
\hline
\end{tabular}

Note. Values in parentheses are converted values to 100-point scale.

${ }^{\mathrm{z}} \mathrm{n}=29$.

${ }^{* *} p<.01$.

Table 5. The effects of Program B for Experimental group ( $N=49)$

\begin{tabular}{|c|c|c|c|c|c|c|c|c|c|}
\hline \multirow{2}{*}{ Item } & \multicolumn{2}{|c|}{ Pre } & \multicolumn{2}{|c|}{ Post } & \multicolumn{2}{|c|}{ Post-Pre } & \multirow{2}{*}{$\mathrm{t}$} & \multirow{2}{*}{$p$} & \multirow{2}{*}{$\mathrm{df}$} \\
\hline & M & SD & M & SD & M & SD & & & \\
\hline Index of greenness & $2.20(36.67)$ & 0.87 & $5.14(85.67)$ & 0.94 & $2.94(49.00)$ & 1.22 & 16.936 & $.000^{* *}$ & \\
\hline Restorative environment & $6.75(67.51)$ & 1.72 & $8.19(81.88)$ & 1.56 & $1.44(14.37)$ & 1.49 & 6.763 & $.000^{* *}$ & \\
\hline Positive emotion & $3.30(65.92)$ & 0.74 & $3.74(74.86)$ & 0.94 & $0.45(8.94)$ & 0.72 & 4.333 & $.000^{* *}$ & \\
\hline Negative emotion & $3.77(75.43)$ & 0.73 & $4.62(92.41)$ & 0.49 & $0.85(16.98)$ & 0.72 & 8.257 & $.000^{* *}$ & \\
\hline Facial expression & $5.06(72.29)$ & 1.07 & $5.92(84.57)$ & 1.02 & $0.86(12.28)$ & 0.96 & 6.267 & $.000^{* *}$ & \\
\hline Psychological assessment & $4.64(66.23)$ & 1.37 & $5.88(84.06)$ & 1.00 & $1.25(17.83)$ & 1.11 & 7.841 & $.000^{* *}$ & \\
\hline
\end{tabular}

Note. Values in parentheses are converted values to 100 -point scale.

${ }^{* *} p<.01$. 
vious research proving that forest therapy programs had positive effects on mental health, stress relief and psychological state (Kim et al., 2013).

\section{Results of analyzing the impact of program im- provement on increasing the therapeutic effect}

To determine the impact of the forest therapy program with improved index of greenness on the increase of therapeutic effect on adolescents, we conducted test for homogeneity of variance and independent samples t-test (one-tailed test) on the score differences before and after the program in the two groups (Table 6). Program B showed a statistically significant improvement in index of greenness and restorative environment compared to Program A, proving that there was a positive impact. Index of greenness was 2.94 points for the experimental group and 2.21 points for the control group, showing an increase of 0.73 points. Restorative environment was 1.44 points for the experimental group and 0.42 points for the control group, showing an increase of 1.02 points. Negative emotion increased by 0.05 points but there was no statistical significance. On the basis of 100 points, index of greenness was affected most by the improvement of the program.

Meanwhile, the control group showed higher scores in positive emotion, facial expression, and psychological assessment. All three categories showed increased pretest and posttest scores by year, but the control group had higher scores or the experimental group showed poor improvement because the pretest scores of the experimental group were somewhat higher than those of the control group, and thus there was little room for improvement in the posttest scores.

Kim et al.(2013) proved that forest therapy programs had positive effects on mental health, stress relief and mentality of elementary school students, and the study by Choi and Ahn (2015) on the elderly discovered that forest therapy affects stability of brain waves and thus has positive effects on mood state. This study on adolescents showed increased posttest scores in both the experimental group and control group, and scores in index of greenness, psychological assessment, positive emotion, and negative emotion increased with statistical significance. This is consistent with the results of previous studies proving that forest therapy is effective in mentality and emotions, and implies that forest therapy has positive effects on all age groups.

According to Lee (2007) and Song (2010), index of greenness and restorative environment had positive effects on emotional recovery, and women showed high tendency of stress reduction and emotional recovery after viewing scenery with high index of greenness. This study also showed the same result as there was a higher ratio of female participants. However, for more accurate comparison, additional research must be conducted according to gender.

Table 6. The comparison of forest therapeutic effect between Program A and Program B

\begin{tabular}{|c|c|c|c|c|c|c|c|c|c|}
\hline \multirow{2}{*}{ Item } & \multicolumn{2}{|c|}{ Program A } & \multicolumn{2}{|c|}{ Program B } & \multicolumn{2}{|c|}{$\begin{array}{c}\text { Homogeneity of } \\
\text { variance test }\end{array}$} & \multicolumn{3}{|c|}{ One side t-test } \\
\hline & M & SD & M & SD & $\mathrm{F}$ & $p$ & $\begin{array}{r}\text { Program B } \\
\text {-Program A }\end{array}$ & $\mathrm{t}$ & $p$ \\
\hline Index of greenness & $2.21(36.78)$ & 1.24 & $2.94(49.00)$ & 1.22 & 0.784 & .379 & $0.73(12.22)$ & 2.555 & $.006^{* *}$ \\
\hline Restorative environment & $0.42(4.26)$ & 2.00 & $1.44(14.37)$ & 1.49 & 0.414 & .522 & $1.02(10.11)$ & 2.567 & $.006^{* *}$ \\
\hline Positive emotion & $0.87(17.43)$ & 1.07 & $0.45(8.94)$ & 0.72 & 4.299 & .041 & $-0.42(-8.49)$ & -1.918 & $.031^{*}$ \\
\hline Negative emotion & $0.81(16.24)$ & 1.10 & $0.85(16.98)$ & 0.72 & 3.137 & .081 & $0.04(0.74)$ & 0.183 & .428 \\
\hline Facial expression & $1.43(20.47)$ & 1.61 & $0.86(12.28)$ & 0.96 & 10.201 & .002 & $-0.57(-8.19)$ & -1.775 & $.042^{*}$ \\
\hline Psychological assessment & $1.54(22.06)$ & 1.56 & $1.25(17.83)$ & 1.11 & 0.775 & .381 & $-0.29(-4.23)$ & -0.981 & .165 \\
\hline
\end{tabular}

Note. Values in parentheses are converted values to 100-point scale.

${ }^{*} p<.05, \stackrel{* *}{p}<.01$. 


\section{Conclusion}

This study was conducted to determine the impact of the forest therapy program with improved index of greenness on the increase of therapeutic effect on adolescents. The subjects are adolescents aged 9 to 18 in Korea Green Ranger that participated in the two-day camp of the National Center for Forest Therapy in 2018 and 2019. We assigned 30 students that participated in the program in 2018 (Program A) to the control group and 51 students that participated in the index of greenness improvement program in 2019 (Program B) to the experimental group. Since the subjects of the two groups that were randomly sampled are not equivalent, the test for homogeneity of variance was conducted to verify the homogeneity of the two groups. This study improved the program with focus on viewing scenery using index of greenness, which is a forest healing resource, and determined whether there is a greater improvement in therapeutic effect.

The experimental group that participated in Program B showed an increase of 0.73 points (12.17 points) in index of greenness and 1.00 points (9.96 points) in restorative environment. This provides that using forest healing resource has an impact on improving the effect of the program. Program B was improved with focus on viewing forest landscape and thus there may have been direct impact on increasing the index of greenness. For restorative environment, the sense of realism was provided as if in a real forest even when the participants are indoors away from the forest, thereby enabling them to feel as if they encountered the natural environment for longer.

This study has significance in proving that active use of forest healing resources helps improve the therapeutic effect, and verifying the utilization value of forest healing resources in developing and improving such programs. Even though the index of greenness improvement program did not have impact on increasing the effects in all categories, the therapeutic effect will be increased in various categories by conducting further research on discovering forest healing resources and utilizing contents related to healing resources.

\section{References}

Choi, G.H. and D.S. Ahn. 2015. Analysis of forest healing effects on senior. J. Recreat. Landsc. 9(2):25-33.

DeLongis, A., J.C. Coyne, G. Dakof, S. Folkman. and R.S. Lazarus. 1982. Relationship of daily hassles, up lifts, and major life events to health status. Health Psychol. 1(2):119-136. https://doi.org/10.1037/0278-6133.1.2.119

Jeon, J.Y. and C.S. Shin. 2017. Effects of indirect forest experience on human psychology. Korean J. Environ. Ecol. 31(4):420-427.

Kanner, A.D., J.C. Coyne, C. Schaefer. and R.S. Lazarus. 1981. Comparisons of two models of stress measurement: Daily hassles and uplifts versus major life events. J. Behav. Med. 4(1):1-39.

Kim, E.S. 2006. Stress and coping style of middle school student's using an school health clinic room. Master's thesis, Kyungpook National University, Daegu, Korea.

Kim, J.Y., C.S. Shin, P.S. Yeoun, J.Y. Yi, M.R. Kim, J.K. Kim. and Y.H. Yoo. 2013. Forest healing program impact on the mental health recovery of elementary school students. J. Korean Inst. For. Recreat. 17(4):69-81. https://doi.org/10.34272/forest.2013.17.4.008

Kim, K.H., S.J. Kwon. and M.Y. Sim. 2005. Test stress and the physical symptom of elementary school students: The moderating effect of ego-resiliency. Korean J. Health Psychol. 10(1):113-126.

Korea Forest Service. 2011. Development of therapeutic program on forests. Daejeon, Korea: Author.

Kwon, E.K. 2018. The effects of daily stress, anxiety, depression and school adjustment on somatization symptoms in adolescents. Master's thesis, Korea University, Seoul, Korea.

Lee, S.H. 2007. The emotion-improving effects of the index of greenness: Focusing on fascination model and restorative environment model. Doctoral dissertation, Chung-Ang university, Seoul, Korea.

Park, B.J. 2010. Experimental approach of therapeutic effect of forest recreation activities: Focused on viewing and walking in forest environments. Doctoral dissertation, Chungnam National University, Daejeon, Korea.

Song, E.H. 2010. The effects of the greenness on adolescent's affect. Master's thesis, Kangwon National University, 
Chuncheon, Korea.

Statistics Korea. 2016. Report on the social survey. Daejeon, Korea: Author.

Statistics Korea. 2018. Report on the social survey. Daejeon, Korea: Author.

Ulrich, R.S. 1984. View through a window may influence recovery from surgery. Science 224(4647):420-421.

Wells, N.M. and G.W. Evans. 2003. Nearby nature: A buffer of life stress among rural children. Environ. Behav. 35(3):311-330. https://doi.org/10.1177/00139165030350 03001 